\title{
STRUCTURAL STUDIES OF $\mathrm{V}_{2} \mathrm{O}_{5}$ DOPED $\mathrm{Li}_{2} \mathrm{CO}_{3}-\mathrm{ZnO}-\mathrm{Al}_{2} \mathrm{O}_{3^{-}}$ $\mathrm{H}_{3} \mathrm{BO}_{3}$ GLASSES
}

\author{
B.Tirumala Rao ${ }^{1}$ and Sandhya Cole ${ }^{2, *}$ \\ ${ }^{1}$ Department of Basic Science, Vishnu Institute of Technology, Bhimavaram-534202, \\ Andhra Pradesh, India. \\ ${ }^{2}$ Department of Physics, Acharya Nagarjuna University, Nagarjuna Nagar, Guntur-522510, \\ Andhra Pradesh, India. \\ *E-mail: sandya.cole@gmail.com
}

\begin{abstract}
In this study, to synthesize various glasses for the system (20-x) $\mathrm{Li}_{2} \mathrm{CO}_{3}-10 \mathrm{ZnO}-5 \mathrm{Al}_{2} \mathrm{O}_{3}-65 \mathrm{H}_{3} \mathrm{BO}_{3}-\mathrm{xV}_{2} \mathrm{O}_{5}$ with ( $\mathrm{x}$ $=0,0.2,0.4,0.6$ and $0.8 \mathrm{~mol} \%$ ) the melt-quenching technique was used. Fourier transform infrared (FT-IR), Electron paramagnetic resonance (EPR) and Ultraviolet-visible (UV-Vis) spectroscopy characterizations are analyzed for the prepared glass samples. The FTIR analyses indicated the presence of various bonds comprising V$\mathrm{O}-\mathrm{V}, \mathrm{B}-\mathrm{O}-\mathrm{B}$, and $\mathrm{B}-\mathrm{OH}$, which were attributed to different vibrations. The presence of $\mathrm{VO}^{2+}$ species was observed in the place of isolated $\mathrm{V}^{4+}$ ions in a ligand field of $\mathrm{C}_{4 \mathrm{v}}$ symmetry from the EPR spectra of these glass samples.From UV-Vis absorption spectra two characteristics bands related to ${ }^{2} \mathrm{~B}_{2} \rightarrow{ }^{2} \mathrm{E}_{1}$ and ${ }^{2} \mathrm{~B}_{2} \rightarrow{ }^{2} \mathrm{~B}_{1}$ transitions of $\mathrm{VO}^{2+}$ are observed in the prepared glass samples.
\end{abstract}

Keywords: Borate Glasses, FT-IR, EPR and UV-Visible Spectroscopy.

@ RASĀYAN. All rights reserved

\section{INTRODUCTION}

Among all types of glasses, borate glasses have the benefit of having the highest glass-forming ability. $\mathrm{B}_{2} \mathrm{O}_{3}$ is a strong glass former because of higher bond strength, lower cationic size and smaller heat of fusion ${ }^{1-2}$. Alkali metal ions like $\mathrm{Li}^{+}$at low concentrations in the borate glasses containing to pure borate glasses is accredited to convert the triangular borate units into the tetrahedrally coordinated borate units without the creation of NBOs, unlike their silicate counter parts ${ }^{3}$. Lithium is the most significant alkaline nature compound and it improves the thermal stability of the borate glasses ${ }^{4}$. The advantages with $\mathrm{ZnO}$ is that it easily makes the coordination with numerous metal ions and substituting $\mathrm{ZnO}$ to oxide glasses is also important due to their non-toxicity, non-hygroscopic nature, lower cost of production, higher polarizability. ${ }^{5-8}$ The additions of alkalies to these zinc borate $(\mathrm{ZnB})$ glasses are accountable for the nonlinear variation of properties. This is really a remarkable change in the properties and has future key applications in optoelectronic and photonic devices. ${ }^{9-10}$

Transition metal ions are incorporated into these glasses in order to characterize their optical behaviors. Glasses containing vanadium oxide $\left(\mathrm{V}_{2} \mathrm{O}_{5}\right)$ have become the subject of interest owing to their potential applications. Vanadium Oxide $\left(\mathrm{V}_{2} \mathrm{O}_{5}\right)$ can act either as a network former or a network modifier in the same glassy network depending on its concentration ${ }^{11}$. Vanadium (V) can exist in various valence states. The main purpose of this present work is to study the Fourier transform infrared (FT-IR), Electron paramagnetic resonance (EPR) and UV-visible spectra of $\mathrm{V}_{2} \mathrm{O}_{5}$ doped Zinc Alumino Lithium borate glasses (Zn-Al-Li-B). This work will facilitate us to specify the existing valencies of vanadium ions in such glass system.

EXPERIMENTAL

The present glass samples $(20-\mathrm{x}) \mathrm{Li}_{2} \mathrm{CO}_{3}-10 \mathrm{ZnO}-5 \mathrm{Al}_{2} \mathrm{O}_{3}-65 \mathrm{H}_{3} \mathrm{BO}_{3}-\mathrm{xV}_{2} \mathrm{O}_{5}$ with $\quad \mathrm{x}=0,0.2,0.4$, 0.6 and $0.8 \mathrm{~mol} \%$ were prepared by the melt quenching method. AnalaR grade chemicals $\mathrm{Li}_{2} \mathrm{CO}_{3}, \mathrm{ZnO}$, $\mathrm{Al}_{2} \mathrm{O}_{3}, \mathrm{H}_{3} \mathrm{BO}_{3}$ and $\mathrm{V}_{2} \mathrm{O}_{5}$ were taken as preparatory materials and required amounts were weighed in a

Rasayan J. Chem., 12(3), 1557-1561(2019)

http://dx.doi.org/10.31788/RJC.2019.1235089

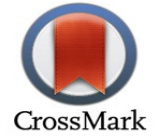


digital balance. The powders were mixed thoroughly to obtain a fine powder in an agate mortar and pestle. The mixtures were taken in a porcelain crucible and placed in an electrically heated furnace. The ingredients were heated at about $950^{\circ} \mathrm{C}$ for $40 \mathrm{~min}$ to get homogeneous melt. The melts were rapidly quenched on a brass plate by pressing it with another brass plate. The glasses so obtained were annealed at temperature $300^{\circ} \mathrm{C}$ below the glass transition temperature to relieve mechanical strains.

The Fourier Transform Infrared spectra of $\mathrm{V}_{2} \mathrm{O}_{5}$ doped zinc alumino lithium borate glasses were recorded on SHIMADZU 8201 PC FT-IR Spectrophotometer in the range $4000-400 \mathrm{~cm}^{-1}$ using KBr pellets. Electron Paramagnetic Resonance spectra were made at room temperature through BRUKER-ER073 series of EPR spectrometer which operates in the X-band frequency $(9.4 \mathrm{GHz})$ at $100 \mathrm{kHz}$ field modulation. The magnetic field was scanned from 0 to $800 \mathrm{mT}$ and the microwave power used was $1 \mathrm{~mW}$. The UV-Vis absorption spectra of the present glasses were recorded using JASCO model V-670 UV-VisNIR spectrophotometer with a resolution of $0.1 \mathrm{~nm}$ at room temperature in the spectral wavelength range covering of $200-900 \mathrm{~nm}$.

\section{RESULTS AND DISCUSSION}

Figure-1 showed clearly FT-IR spectra of present glass samples. Meanwhile, the literature and are interrelated to various borate glass structures were indicated the assignment of different vibrational modes. Borate glasses are mostly composed of $\mathrm{BO}_{3}$ triangle and $\mathrm{BO}_{4}$ pyramidal groups and it depends on the additive to borate glass. A band at $450 \mathrm{~cm}^{-1}$ is attributed to vibration of the $\mathrm{Zn}^{+2}$ metal cations ${ }^{12-13}$. A band at $480 \mathrm{~cm}^{-1}$ is a reliable proof of the presence of vibrations of $\mathrm{Li}^{+}$cations against their network sites ${ }^{14}$ and band at $710 \mathrm{~cm}^{-1}$ is due to the bending of B-O-B linkage ${ }^{15}$. Band at $1040 \mathrm{~cm}^{-1}$ may be due to $\mathrm{B}-\mathrm{O}$ stretching vibration in $\mathrm{BO}_{4}$ units which present in different borate groups ${ }^{16}$. The observed band at about $1410 \mathrm{~cm}^{-1}$ will be attributed to the $\mathrm{B}-\mathrm{O}$ stretching vibration of $\mathrm{BO}_{3}$ in pentaborate, pyroborate, orthoborate groups ${ }^{17}$. The absorption bands around $1640-3950 \mathrm{~cm}^{-1}$ in the spectra glasses are due to the water, $\mathrm{O}-\mathrm{H}$ stretching vibrations, or $\mathrm{BOH}$ groups ${ }^{18-19}$. Due to the incorporation of moisture during sample preparation for FT-IR spectroscopy, the $\mathrm{OH}^{-}$groups may be present. Only minor variations in the intensity of some bands are identified with an increment of vanadium concentration by the careful inspection on the FT-IR spectra. The observed results can thus be interpreted by assuming that vanadium concentration causes some limited variations in the bond angles and/or bond lengths within the structural groups.

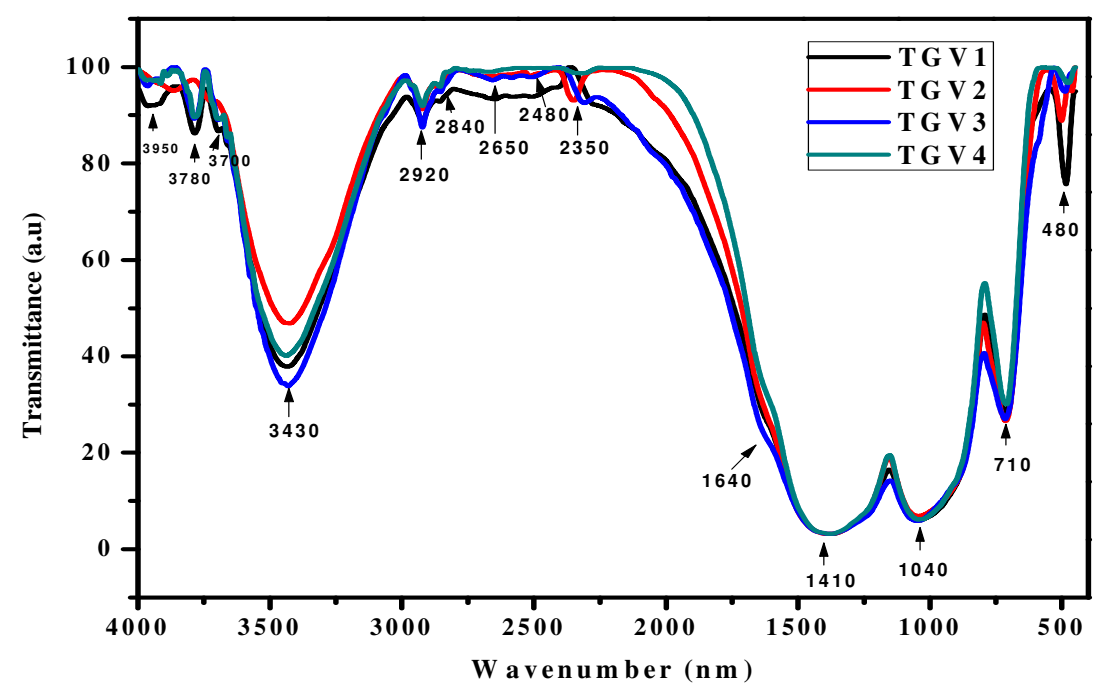

Fig.-1: FT-IR Spectra of Vanadium Doped Zinc Alumino Lithium Borate Glasses

The EPR spectra of $\mathrm{VO}^{2+}$ ions in the present glass system clearly showed in Fig.-2. The EPR signal is of three types. (a) Is due to the high concentration of vanadium. If the vanadium content in the compound is high, it gives a broad resonance line. As a result, the hyperfine line from ${ }^{51} \mathrm{~V}$ cannot be resolved. The $\mathrm{g}$ 
RASĀYAN J. Chem.

Vol. 12 | No. 3 |1557 - 1561| July - September | 2019

value for this resonance is less than 2. (b) $\mathrm{VO}^{2+}$ ion has $\mathrm{s}=1 / 2$ and $\mathrm{I}=7 / 2$. The EPR spectrum shows a hyperfine pattern of eight equidistant lines. $\mathrm{In}_{4 \mathrm{v}}$ symmetry, two sets of eight lines are expected, whereas in $\mathrm{C}_{2 \mathrm{v}}$ symmetry three sets of eight lines are expected. Further in tetragonal distortion, $g_{\|}<g_{\perp}<g_{e}$ which shows the presence of an unpaired electron in the $d_{x y}$ orbital. This is a characteristic feature of a tetragonally compressed complex. The EPR spectra were analyzed by using the spin-Hamiltonian equation $^{20}$, is given below

$H=\beta\left[g_{\|} H_{\mathrm{z}} S_{\mathrm{z}}+g_{\perp}\left(H_{\mathrm{x}} S_{\mathrm{x}}+H_{\mathrm{y}} S_{\mathrm{y}}\right)\right]+A_{\|} S_{\mathrm{z}} I_{\mathrm{z}}+A_{\perp}\left(S_{\mathrm{x}} I_{\mathrm{x}}+S_{\mathrm{y}} I_{\mathrm{y}}\right)$

where $\beta$ is the Bohr magneton, $g_{\|}$and $g_{\perp}$ are the parallel and perpendicular principal components of the $g$ tensor, $A_{\|}$and $A_{\perp}$ are the parallel and perpendicular principal components of the hyperfine coupling tensors, $H_{\mathrm{x}}, H_{\mathrm{y}}$ and $H_{\mathrm{z}}$ are the components of the magnetic field, $S_{\mathrm{x}}, S_{\mathrm{y}}$ and $S_{\mathrm{z}}$ and $I_{\mathrm{x}}, I_{\mathrm{y}}$ and $I_{\mathrm{z}}$ are the components of the spin operators of the electron and nucleus respectively. The spin-Hamiltonian parameters of $\mathrm{VO}^{2+}$ ions were determined and are given in Table-1. The $g_{\text {iso }}$ values $\left[g_{\text {iso }}=\left(g_{\|}+2 g_{\perp}\right) /\right.$ $3]$ and $A_{i s o}$ values $\left[A_{\text {iso }}=\left(A_{\|}+A_{\perp}\right) / 3\right.$ ] were also calculated and are presented in Table- 1 .

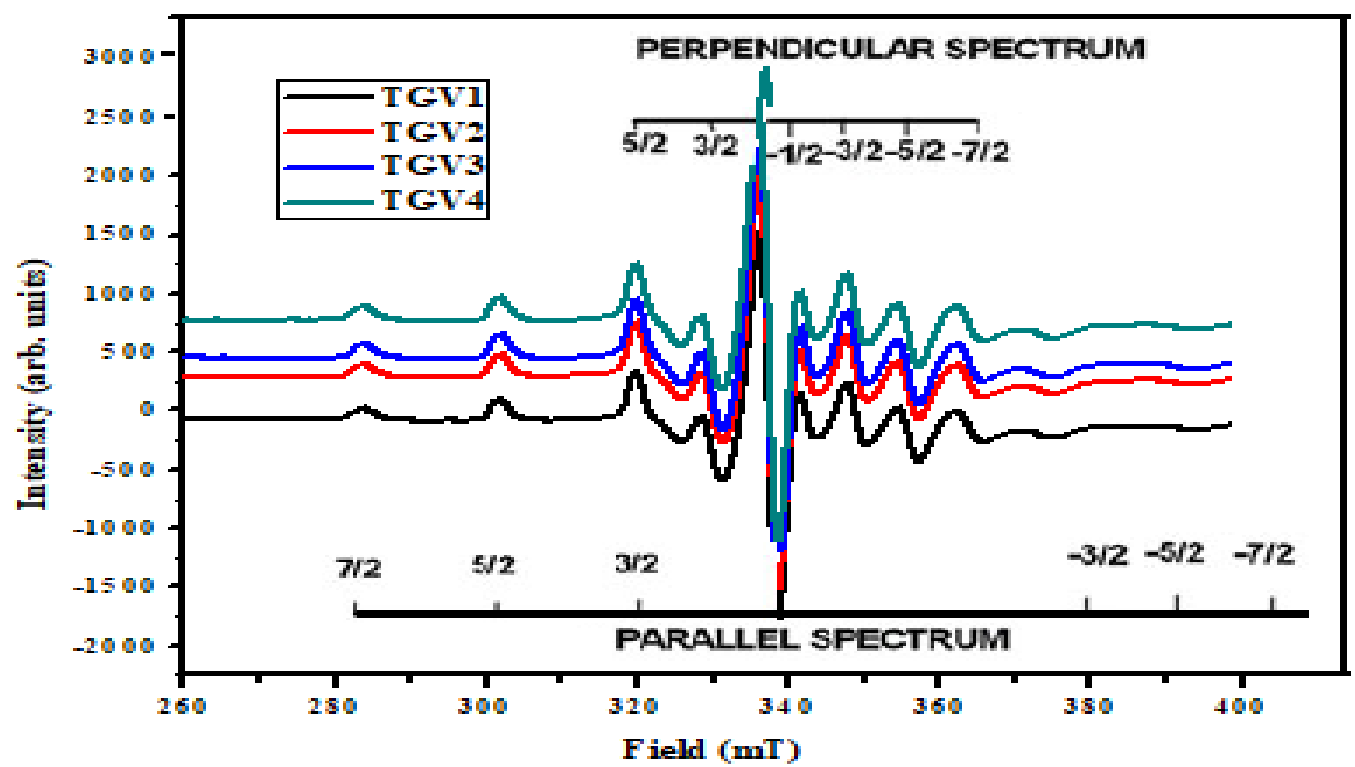

Fig.-2: EPR Spectra of Vanadium Doped Zinc Alumino Lithium Borate Glasses

With the increase of concentration of $\mathrm{V}_{2} \mathrm{O}_{5}$ concentration the intensity and resolution of EPR spectra increases and it is attributed to increasing in the concentration of $\mathrm{V}^{4+}$ ions and also due to structural and micro structural modifications, which produce fluctuations of the degree of deformation or even of the coordination geometry of $\mathrm{V}^{4+} \operatorname{sites}^{21-22}$. It is also concluded that $\mathrm{V}^{4+}$ ions exist as $\mathrm{VO}^{2+}$ ions in octahedral coordination with a tetragonal compression with $C_{4 \mathrm{~V}}$ symmetry and that the ground state is $d_{\mathrm{xy}}$ orbital from the values presented in Table-1.

Table-1: Spin-Hamiltonian Parameters of Vanadium Doped Zinc Alumino Lithium Borate Glasses

\begin{tabular}{c|c|c|c|c|c|c}
\hline Glass & $g_{\|}$ & $g_{\perp}$ & $A_{\|}$ & $A_{\perp}$ & $g_{\text {iso }}$ & $A_{\text {iso }}$ \\
\hline TGV1 & 1.9281 & 1.9639 & 178.1951 & 63.1507 & 1.9519 & 80.4486 \\
\hline TGV2 & 1.9263 & 1.9632 & 179.1886 & 63.2011 & 1.9509 & 80.7965 \\
\hline TGV3 & 1.9252 & 1.9618 & 179.1843 & 63.5308 & 1.9496 & 80.9050 \\
\hline TGV4 & 1.9264 & 1.9627 & 179.1250 & 63.5127 & 1.9506 & 80.8792 \\
\hline
\end{tabular}

The Optical absorption spectra of present glasses are shown in Fig.-3. Pure glass did not exhibit any visible bands. The visible absorption bands are observed to be more intensified with the increase of $\mathrm{V}_{2} \mathrm{O}_{5}$ content. 


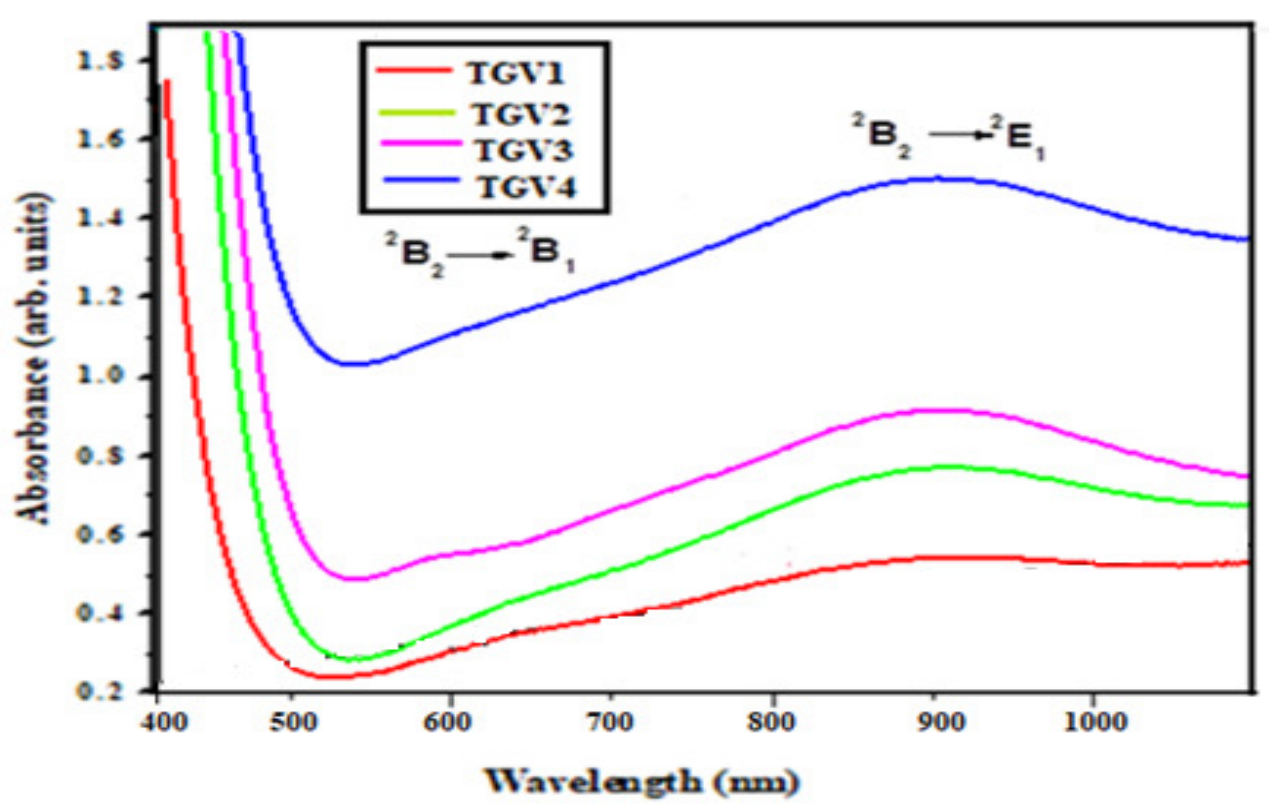

Fig.-3: Optical Absorption Spectra of Vanadium Doped Zinc Alumino Lithium Borate Glasses

The spectra of all glasses exhibited a small broad band centered at about $520 \mathrm{~nm}$ and with a resolution of a new broad band centered at about $908 \mathrm{~nm}$, corresponding to ${ }^{2} \mathrm{~B}_{2} \rightarrow{ }^{2} \mathrm{E}_{1}$ and ${ }^{2} \mathrm{~B}_{2} \rightarrow{ }^{2} \mathrm{~B}_{1}$ transitions of $\mathrm{VO}^{2+}$. The width and peak height of these bands are observed to increases, with gradual increment in the concentration of $\mathrm{V}_{2} \mathrm{O}_{5}$. Therefore these bands are observed to take a red shift. These absorption peaks are characteristic of $\mathrm{V}^{4+}$ ions with a distorted octahedral site. Assignment of the absorption bands are made in the light of energy level scheme for molecular orbitals of the $\mathrm{VO}^{2+}$ ions in a ligand field of $\mathrm{C}_{4 \mathrm{v}}$ symmetry. $^{23}$

\section{CONCLUSION}

In this study, analyses based on FT-IR, EPR, and UV-Vis spectra were conducted for all of the synthesized glass samples in order to determine their structural and optical properties. FTIR spectra showed that the increment of vanadium oxide caused the breaking of B-O-B bonds. EPR spectra were influenced by the variation of concentration of $\mathrm{V}_{2} \mathrm{O}_{5}$. It concluded that $\mathrm{V}^{4+}$ ions exist as $\mathrm{VO}^{2+}$ ions in octahedral coordination with a tetragonal compression with $C_{4 \mathrm{~V}}$ symmetry and that the ground state is $d_{\mathrm{xy}}$ orbital.

\section{REFERENCES}

1. I. Kindrat, B. V. Padlyak and A. Drzewiecki, Journal of Luminescence, 166, 264(2015), DOI:10.1016/j.jlumin.2015.05.051B.

2. V. Padlyak, I. I. Kindrat, V. O. Protsiuk and A. Drzewiecki, Ukrainian Journal of Physical Optics, 15(3), 103(2014), DOI:10.3116/16091833/15/3/103/2014

3. A. Sheoran, A. Agarwal, S. Sanghi, V. P. Seth, S.K. Gupta and M. Arora, Physica B, 406(23), 4505(2011), DOI:10.1016/j.physb.2011.09.017

4. A. Lewis, U. S. Patent US 7189671, (2007)

5. V. Ganesh, I. S. Yahia, S. AlFaify and Mohd. Shkir, Journal of Physics and Chemistry of Solids 100, 115(2017), DOI:10.1016/j.jpcs.2016.09.022

6. R. Vijaya, V. Venkatramu, P. Babu, C. K. Jayasankar, U. R. RodrÍguez-Mendoza and V. Lavin, Journal of Non-Crystalline Solids, 365, 85(2013), DOI:10.1016/j.jnoncrysol.2013.01.030

7. V. Adelene Prathyusha and D. Punyaseshudu, Rasayan Journal of Chemistry 10(6), 771(2017), DOI: 10.7324/RJC.2017.1031742

8. V. Adelene Prathyusha and D. Punyaseshudu, Rasayan Journal of Chemistry 10(6), 881(2017), DOI:10.7324/RJC.2017.1031743 
RASĀYAN J. Chem.

Vol. 12 | No. 3 |1557 - 1561| July - September | 2019

9. M. V. Sasi Kumar, D. Rajesh, A. Balakrishna and Y.C. Ratnakaram, Physica B, 415, 67(2013), DOI:10.1016/j.physb.2013.02.004

10. P. Godlewska, Sz. Bandrowski, L. Macalik, R. Lisiecki, W. Ryba-Romanowsky, I. Szczyeiel, P. Ropuszynska-Robak and J. Hanuza, Optical Materials 34(7), 1023(2012), DOI:10.1016/j.optmat.2011.12.014

11. S. Das, A. Madheshiya, M. Ghosh, K. K. Dey, S. S. Gautam, J. Singh, R.Mishra and C. Gautam, Journal of Physics and Chemistry of Solids, 126 17(2019), DOI:10.1016/j.jpcs.2018.10.030.

12. E. I . Katnitsos, M. A. Karakassides and G. D. Chryssikos, The Journal of Physical Chemistry, 91(22), 5807(1987), DOI:10.1021/j100306a058

13. G. J. Exarhos and W. M. Risen, Chemical Physics Letters 10,484(1971)

14. P. Tarte, In Proceedings of the International Conference of Non-Crystalline Solids in physics, Amsterdam pp 549 (1964)

15. S. M. Abo-Naf, Journal of Non-Crystalline Solids, 358(2), 406(2012), DOI:10.1016/j.jnoncrysol.2011.10.013

16. S. Rani, S. Sanghi, A. Agarwal and N. Kishore, Solid State Phenomena, 161, 51(2010), DOI:10.4028/www.scientific.net/SSP.161.51

17. I. I. Plyusnina, Infrakrasnye spektry mineralov (Infrared Spectra of Minerals), Moscow: Moscow State University, 1976.

18. Md. Rafiqul Ahsan, M. Golam Mortuza, Journal of Non-Crystalline Solids, 351(27-29), 2333(2005), DOI:10.1016/j.jnoncrysol.2005.05.030

19. F. H. El-Batal, E. M. Khalil, Y. M. Hamdy, H.M. Zidan, M. S. Aziz and A.M. Abdelghany, Silicon, 2(1), 41(2010), DOI:10.1007/s12633-010-9037-8

20. A. Abragam and B. Bleaney, Electron Paramagnetic Resonance of Transition ions, Clarendon Press, Oxford, 175. 1970

21. M. Chandra Sekhar Reddy, E. Ramesh Kumar, B. Appa Rao, International.Journal of Scientific \&.Engineering Research. 5, 232 (2014)

22. Abdul Hameed, B. Srinivas, A. Edukondalu, M. Shareefuddin, M. Narasimha Chary, Physics and Chemistry of Glasses - European Journal of Glass Science and Technology Part B, 56(6), 263(2015), DOI: $10.13036 / 17533562.56 .5 .263$

23. R. P. Sreekanth Chakradhar, A. Murali and J. L. Lakshmana Rao, Physica B, 293(1-2), 108(2000), DOI: 10.1016/S0921-4526(00)00529-9

[RJC-5280/2019] 